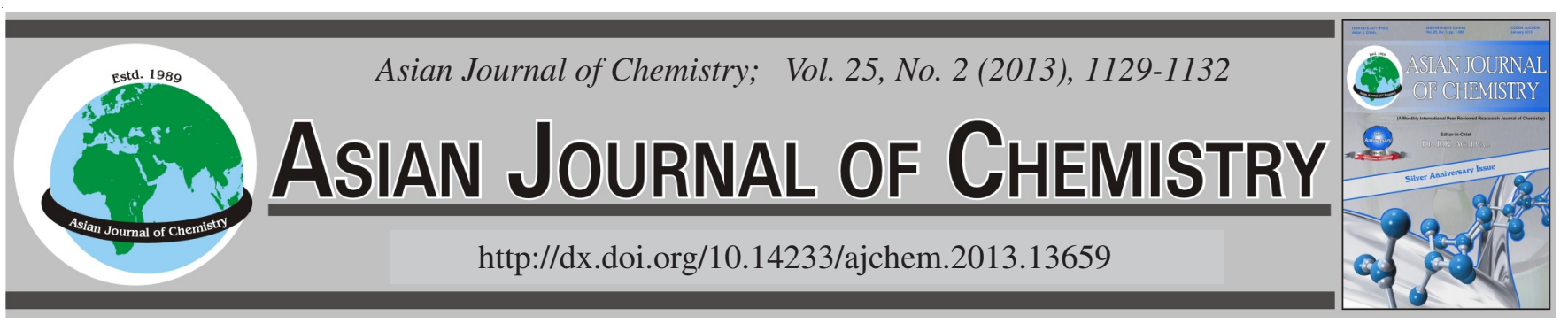

\title{
Determination of Polycyclic Aromatic Hydrocarbons in Soil Sample Using Matrix Solid Phase Dispersion-Stable Isotope Dilution Technique-Gas Chromatography Mass Spectrometry
}

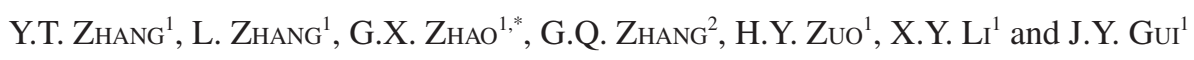

${ }^{1}$ Institute of Hydrogeology and Environmental Geology, CAGS, Zhengding 50803, P.R. China

${ }^{2}$ Weichai Power Co., Ltd. Weifang 261001, P.R. China

*Corresponding author: E-mail: icpzytws@126.com; zhaoGuoxing65@163.com

(Received: 27 February 2012;

Accepted: 31 August 2012)

AJC-12058

A method was developed for the determination of polycyclic aromatic hydrocarbons (PAHs) in soil sample by measuring stable isotope
dilution technique of matrix solid-phase dispersion extraction-gas chromatography mass spectrometry. The sample adopted silica with
bonded C18 as solid supports, used dichloromethane-acetone to elute and realized cleaning and recovery. The research verified the similar
physicochemical properties and the consistency of chromatographic behaviour between target compounds and compounds containing
deuterium, confirmed that isotope fractionation was not obvious during the sample pretreatment in this experiment. The recovery of
standard addition was between 97.5 to $109.2 \%$, the precision was between 0.89 and $3.06 \%$ and achieved satisfactory recovery.

Key Words: Matrix solid phase dispersion, Isotope dilution technique, Polycyclic aromatic hydrocarbons, Gas chromatography mass spectrometry.

\section{INTRODUCTION}

Polycyclic aromatic hydrocarbons (PAHs) are hydrophobic compounds which have two or more benzene rings and are arranged in lines, corneates or bounches. They have teratogenicity, carcinogenicity and mutagenecity effects ${ }^{1}$, genotoxicity on organism and potential hazardous effects on human body ${ }^{2}$. Polycyclic aromatic hydrocarbons exist widely in the atmosphere, waters and soil ${ }^{3}$. Soil is an important media for various substances exchange, a compilation place and transfer station for polycyclic aromatic hydrocarbons in environment. Polycyclic aromatic hydrocarbons pollution in soil is becoming more and more serious; polycyclic aromatic hydrocarbons concentration in soil (especially in urban areas) is continuously increasing ${ }^{4}$. In recent years, Chinese scholars have done numerous researches based on site investigation about polycyclic aromatic hydrocarbons pollution in soil. The results showed that 16 priority monitoring polynuclear aromatic hydrocarbons set by United States Environmental Protection Agency (US EPA) in China's soil were detected in different degree and the detection rate was very high ${ }^{5,6}$.

In order to better understand the changing law of polycyclic aromatic hydrocarbons' pollution and transfer in soil, we must develop effective and accurate quantitative analysis method to detect polycyclic aromatic hydrocarbons in soil. The commonly used polycyclic aromatic hydrocarbons instrument analysis methods consist of gas chromatography ${ }^{7,8}$, high performance liquid chromatography ${ }^{1,4,9}$, gas chromatography mass spectrometry ${ }^{3,10}$, etc. The pretreatment methods of polycyclic aromatic hydrocarbons in soil have Soxhlet extraction, ultrasonic extraction ${ }^{1,4,11}$, accelerated solvent extraction $^{3,12}$, supercritical fluid extraction and so on. Matrix solid-phase dispersion in QuEChERS is a rapid, efficient and much more environmental-friendly sample pretreatment method in vogue internationally in recent years ${ }^{13-16}$; there have been organic pollutants studies on food, soil and other samples ${ }^{17}$. It can effectively decrease the backgrounds of the samples and integrate the extraction and cleaning-up of the samples. Isotope dilution technique is an important accurate quantitative analyzing method ${ }^{18,19}$, but is seldom implemented in complicated matrix sample. While there has not been any report about using matrix solid phase dispersion-stable isotope dilution technique to detect polycyclic aromatic hydrocarbons in soil. This experiment adopted $\mathrm{C} 18$ matrix solid phase dispersion to carry on soil sample pretreatment, which effectively decreased the matrix background of the sample. By studying isotope fractionation effect of sample pretreatment and stabilizing isotope dilution technique to effectively correct the loss occurring during pretreatment, which could determine more accurately the quantity of polycyclic aromatic hydrocarbons. Results showed that method used in this experiment could effectively eliminate the interference of base and get quantifi- 
cation results and therefore has certain extension research value.

\section{EXPERIMENTAL}

TRACE DSQII gas chromatography mass spectrometry (U.S. Company Thermo Fisher), solid phase extraction element (Tianjin Heng'ao Company), nitrogen evaporator (Tianjin Automatic Science Instrument Co.,LTD), constant temperature water bath apparatus.

Dichloromethane (pesticide residue grade), acetone (pesticide residue grade), $n$-hexane (pesticide residue grade), anhydrous sodium sulfate (excellent pure,bake at $600{ }^{\circ} \mathrm{C}$ ), silica, C18 bonded silica, Florisil from SUPELCO, 16 polycyclic aromatic hydrocarbons and Deuterated Compounds from Sigma-Aldrich company.

Choice of column and instrument requirement: Column: DB-5MS quartz capillary column $(30 \mathrm{~m} \times 0.25 \mathrm{~mm} \times 0.25$ $\mu \mathrm{m})$; carrier gas: high purity helium gas $(99.999 \%)$; chromatogram temperature program: initial temperature at $40{ }^{\circ} \mathrm{C}$ and maintain for $1 \mathrm{~min}$; Raise temperature at speed of $7{ }^{\circ} \mathrm{C}$ per min to $120^{\circ} \mathrm{C} ; 10^{\circ} \mathrm{C}$ per min to $220^{\circ} \mathrm{C} ; 5^{\circ} \mathrm{C}$ per min to $300^{\circ} \mathrm{C}$, keep it for $5 \mathrm{~min}$.

Injection port temperature: $240^{\circ} \mathrm{C}$; joint lever temperature: $260{ }^{\circ} \mathrm{C}$; ion source temperature: $250^{\circ} \mathrm{C}$; injection pattern: Splitless Injecting samples $1 \mu \mathrm{L}$; solvent delay time: 6 min; scanning system: Segment selected ion monitoring.

Preparation and abstraction of sample: Accurately weigh $0.50 \mathrm{~g}$ natural drying soil sample (grinding $100 \mathrm{mesh}$ ), $2.0 \mathrm{~g} \mathrm{C} 18$ solid-phase filler, put them in agate mortar, grind uniformly, add isotope diluents and mix uniformly. Put small mass of absorbent cotton purified by methylene dichloride at the bottom of columella, add $2 \mathrm{~g}$ anhydrous sodium sulfate, $0.5 \mathrm{~g}$ mixture of copper powder in order and grind sample. Hammer podetium lightly, compact and place it on solid-phase extraction device, use mixed solution of dichloromethane and acetone $\left(\mathrm{CH}_{2} \mathrm{Cl}_{2}: \mathrm{CH}_{3} \mathrm{COCH}_{3}=\mathrm{v} / \mathrm{v}\right.$ 2:1) as eluent. Infiltrate column for $5 \mathrm{~min}$ in eluent, then add $6 \mathrm{~mL}$ elution solvent in twice, elute sample naturally by gravity, filtrate after that and collect eluate. Use gas chromatography mass spectrometry to detect after concentrating to $0.5 \mathrm{~mL}$ by water bath.

\section{RESULTS AND DISCUSSION}

Choice of mass spectrometry scanning: Optimize gas chromatography separation procedures, use mass spectrum full-scan to obtain compounds and reference ions and quantitative ions of their isotope diluents (Table-1). When analyzing sample, in order to improve the sensitivity of instrument, segment selected ion monitoring scan is applied. That is to say, only scanning ion of interest in different time quantum could significantly improve the sensitivity of instrument and eliminate the effect of some matrix. The method tested the response caused by the change of mass spectrometry's scanning parameters dewell. Condition tests for $100 \mathrm{~min}, 70 \mathrm{~min}, 50$ min, $40 \mathrm{~min}$, $30 \mathrm{~min}, 20 \mathrm{~min}, 10 \mathrm{~min}$ were made under the same concentration standard sample. The smaller of parameters dwell, the more peak point number, which contributes to accurate quantitative of peak area. There is no big change of signal-to-noise ratio, while low resolution could decrease peak resolution. Therefore, giving condition to resolution and peak area, we chose setting to $30 \mathrm{~min}$.

Isotope fractionation behaviour analysis of analyte and stable isotope dilutuion: Stable isotope dilution and analyte have similar physical and chemical properties and could keep similar behaviour in pretreatment and chromatographic separation. Therefore, the quantitative accuracy of isotope dilution technique achieved general accreditation in analysis field. Meanwhile, the sample's isotope fractionation raised attention in pretreatment ${ }^{20,21}$. The method investigated the change of isotope fractionation of analyte and stable isotope dilution in pretreatment and chromatographic behaviour, parallel determined standard sample adding isotope dilution for 10 times and acquired 10 area rations of analyte and isotope dilution, expressed by $\eta_{\mathrm{st}}$.

$$
\eta_{\mathrm{st}}=\frac{\mathrm{A}_{\mathrm{s}}}{\mathrm{A}_{\mathrm{i}}}
$$

TABLE-1

RETENTION TIME, QUOTA ION, REFERENCE ION OF 16 POLYCYCLIC AROMATIC HYDROCARBONS AND DEUTERATED COMPOUNDS

\begin{tabular}{|c|c|c|c|c|c|c|c|}
\hline Compounds & $\mathrm{R}_{\mathrm{t}}$ & $\begin{array}{l}\text { Quantitative } \\
\text { ion }(\mathrm{m} / \mathrm{z})\end{array}$ & $\begin{array}{l}\text { Reference } \\
\text { ion }(\mathrm{m} / \mathrm{z})\end{array}$ & Deuterated compounds & $\mathrm{R}_{\mathrm{t}}$ & $\begin{array}{l}\text { Quantitative } \\
\text { ion }(\mathrm{m} / \mathrm{z})\end{array}$ & $\begin{array}{l}\text { Reference } \\
\text { ion }(\mathrm{m} / \mathrm{z})\end{array}$ \\
\hline Acenaphthene & 11.32 & 128 & 129,127 & Acenaphthene-D8 & 11.28 & 136 & 137,135 \\
\hline Acenaphthylene & 15.76 & 152 & 151,153 & Acenaphthylene-D8 & 15.72 & 160 & 159,161 \\
\hline Acenaphthene & 16.25 & 154 & 153,152 & D10 Acenaphthene-D10 & 16.21 & 164 & 163,162 \\
\hline Fluorene & 17.53 & 166 & 165,167 & Fluorene-D10 & 17.49 & 176 & 175,177 \\
\hline Phenanthrene & 19.86 & 178 & 179,176 & Phenanthrene-D10 & 19.81 & 188 & 189,186 \\
\hline Anthracene & 19.97 & 178 & 179,176 & Anthracene-D10 & 19.92 & 188 & 189,186 \\
\hline Fluoranthene & 22.83 & 202 & 101,203 & Fluoranthene-D10 & 22.78 & 212 & 211,213 \\
\hline Pyrene & 23.44 & 202 & 200,203 & Pyrene-D10 & 23.28 & 212 & 210,213 \\
\hline Benzo(a)anthracene & 27.46 & 228 & 229,226 & Benzo(a)anthracene-D12 & 27.40 & 240 & 241,238 \\
\hline Chrysene & 27.60 & 228 & 226,229 & Chrysene-D12 & 27.53 & 240 & 238,241 \\
\hline Benzo(b)fluoranthene & 31.48 & 252 & 253,125 & Benzo(b)fluoranthene-D12 & 31.41 & 264 & 265,137 \\
\hline Benzo(k)fluoranthene & 31.57 & 252 & 253,125 & Benzo(k)fluoranthene-D12 & 31.50 & 264 & 265,137 \\
\hline Benzo(a)pyrene & 32.62 & 252 & 253,125 & Benzo(a)pyrene-D12 & 32.54 & 264 & 265,137 \\
\hline Indeno(1,2,3-cd)pyrene & 36.49 & 276 & 138,277 & Indeno(1,2,3-cd)pyrene-D12 & 36.40 & 288 & 150,289 \\
\hline Dibenz(a,h)anthracene & 36.64 & 278 & 139,279 & Dibenz(a,h)anthracene-D14 & 36.54 & 292 & 153,293 \\
\hline $\operatorname{Benzo}(\mathrm{g}, \mathrm{h}, \mathrm{i})$ perylene & 37.26 & 276 & 138,277 & Benzo(g,h,i)perylene-D12 & 37.15 & 288 & 150,289 \\
\hline
\end{tabular}


TABLE-2

AVERAGE $\eta_{\mathrm{st}}$ AND SLOPE (K)

\begin{tabular}{lcccccccc}
\hline \multicolumn{1}{c}{ Compound } & Nap & AcPy & Acp & Flu & PhA & AnT & FluA & Pyr \\
\hline$\eta_{\text {st }}$ Average & 1.10 & 0.81 & 1.00 & 1.13 & 0.52 & 0.71 & 0.85 & 1.13 \\
RSD $(\%)$ & 1.23 & 0.67 & 1.03 & 1.34 & 1.87 & 1.37 & 0.65 & 0.87 \\
Slope $(\mathrm{k})$ & 1.1247 & 0.8078 & 1.0221 & 1.1076 & 0.5584 & 0.6947 & 0.8313 & 1.1060 \\
\hline Compound & BaA & Chr & BbF & BkF & Bap & IcdP & DbA & BghiP \\
\hline$\eta_{\text {st }}$ Average & 0.75 & 0.69 & 0.90 & 1.14 & 0.82 & 1.22 & 0.83 & 0.66 \\
RSD $(\%)$ & 0.88 & 1.12 & 1.05 & 1.32 & 1.83 & 1.36 & 2.28 & 2.33 \\
Slope (k) & 0.7726 & 0.6832 & 0.9241 & 1.1238 & 0.8333 & 1.2078 & 0.8164 & 0.6383 \\
\hline
\end{tabular}

Nap = Acenaphthene, AcPy $=$ Acenaphthylene, Acp $=$ Acenaphthene, Flu $=$ Fluorene, PhA $=$ Phenanthrene, AnT $=$ Anthracene, FluA $=$ Fluoranthene, $\mathrm{Pyr}=$ Pyrene, $\mathrm{BaA}=\mathrm{Benzo}(\mathrm{a})$ anthracene, $\mathrm{Chr}=$ Chrysene, $\mathrm{BbF}=\mathrm{Benzo}(\mathrm{b})$ fluoranthene, $\mathrm{BkF}=\mathrm{Benzo}(\mathrm{k})$ fluoranthene, $\mathrm{Bap}=$ Benzo(a)pyrene, DbA = Dibenz(a,h)anthracene, BghiP = Benzo(g,h,i)perylene. IcdP = Indeno(1,2,3-cd)pyrene.

$\mathrm{A}_{\mathrm{s}}=$ peak area of standard samples' analyte, $\mathrm{A}_{\mathrm{i}}=$ peak area of standard samples analyte's correspondent isotope dilution.

Table- 2 showed the average of $\eta_{\mathrm{st}}$ in 10 tests, precision (RSD) of 16 polycyclic aromatic hydrocarbons. Precision (RSD) was lower than $2.5 \%$ in Table-2, which showed that sample's polycyclic aromatic hydrocarbons' isotope ratio had excellent reproducibility during mass spectrometry's determination period and could ensure that analyte and isotope dilution had similar behaviour during chromatographic separation. Add low, middle and high-concentration of analyte and correspondent isotope dilution to 10 quartz sand samples, detect on the machine after pretreatment according to this method procedure. With peak area of adding standard substance as ordinate, correspondent isotope dilution as abscissa, the analysis of linear fit of data point and correlation coefficients was over 0.995. Slope of the curve fitting was showed in Table-2.

It showed from the table that curve slope was very close to the average of $10 \eta_{\mathrm{st}}$ sample, which indicated that the isotope fractionation of the sample during pretreatment and detection process was stable and proved the applicability of isotope dilution technique used in the method.

Effect of pretreatment reagents: In most literature, dichloromethane, dichloromethane- $n$-hexane, dichloromethane-acetone were usually adopted as soil extraction reagents, while this method also gave attention to the elution efficiency and purification effect of elution solvent. Dichloromethane- $n$-hexane $(\mathrm{v} / \mathrm{v}=1: 1)$, dichloromethane-acetone $(\mathrm{v} / \mathrm{v}$ $=1: 1), n$-hexane-acetone $(\mathrm{v} / \mathrm{v}=1: 1)$ and dichloromethane were used as elution solvent to carry on test. The results showed different elution efficiency: dichloromethane-acetone $>n$ hexane-acetone $>$ dichloromethane $>$ dichloromethane$n$-hexane.

Selection of matrix solid phase dispersant and cleaning principle conjecture: Matrix solid phase dispersion (MSPD) is a pretreatment method similar to solid phase extraction which integrates extraction and purification: uniformly grind soil sample and matrix solid phase dispersant, put it in column, chose different elution solvent to leach and could then extract and purify target compound. This method used florisil, C18 bonded silica and pickling silica as matrix solid phase dispersant and found that $\mathrm{C} 18$ bonded silica had good purification effect after comparative study. Principle presumed: C18 bonded silica surface functional groups could effectively disperse on the solid phase dispersant surface because of the mutual adsorption of vanderwaals force or dispersion force and polycyclic aromatic hydrocarbons in the soil, thus effectively separate from soil sample matrix, destroy the van der Waals force caused by the polycyclic aromatic hydrocarbons and $\mathrm{C} 18$ bonded silica by using proper amount of non-polar solvent and thus achieved elution. This method determined $\mathrm{C} 18$ bonded silica as the solid phase dispersant of soil sample.

Recovery, RSD and LODs: Carefully weigh 10 portions of $0.5 \mathrm{~g}$ quartz sand, add matrix solid phase, add $10 \mathrm{ng}$ standard, test all technological process according to this method, detect on the machine, make signal-to-noise ratio for three correspondent concentration as LOD and calculate the precision (RSD). Use stable isotope dilution technique to quantitative, calculate the recovery efficiency $(\%)$ and related parameters were shown in Table-3.

\section{TABLE-3}

THE RECOVERY, RSD AND LIMIT OF DETECTION (LOD)

\begin{tabular}{lcccc}
\hline \multicolumn{1}{c}{ Compounds } & $\begin{array}{c}\text { Spiked } \\
(\mu \mathrm{g} / \mathrm{Kg})\end{array}$ & $\begin{array}{c}\text { Recoveries } \\
(\%)\end{array}$ & $\begin{array}{c}\mathrm{RSD} \\
(\%, \mathrm{n}=10)\end{array}$ & $\begin{array}{c}\mathrm{LOD} \\
(\mu \mathrm{g} / \mathrm{Kg})\end{array}$ \\
\hline Acenaphthene & 20.0 & 105.8 & 2.81 & 0.85 \\
Acenaphthylene & 20.0 & 101.3 & 0.97 & 0.95 \\
Acenaphthene & 20.0 & 96.5 & 1.38 & 1.36 \\
Fluorene & 20.0 & 95.6 & 1.68 & 0.37 \\
Phenanthrene & 20.0 & 92.3 & 2.31 & 0.68 \\
Anthracene & 20.0 & 96.3 & 1.65 & 0.56 \\
Fluoranthene & 20.0 & 89.8 & 0.89 & 1.75 \\
Pyrene & 20.0 & 88.7 & 1.03 & 0.89 \\
Benzo(a)anthracene & 20.0 & 92.5 & 1.23 & 1.32 \\
Chrysene & 20.0 & 102.5 & 1.38 & 1.54 \\
Benzo(b)fluoranthene & 20.0 & 97.8 & 1.65 & 0.76 \\
Benzo(k)fluoranthene & 20.0 & 96.7 & 1.78 & 0.47 \\
Benzo(a)pyrene & 20.0 & 90.2 & 2.13 & 0.56 \\
Indeno(1,2,3-cd)pyrene & 20.0 & 88.5 & 1.54 & 1.38 \\
Dibenz(a,h)anthracene & 20.0 & 93.6 & 2.96 & 2.56 \\
Benzo(g,h,i)perylene & 20.0 & 94.8 & 3.06 & 2.89 \\
\hline
\end{tabular}

Real sample analysis: We adopted this method to analyze soil samples of different matrix and the results of the realistic samples were showed in the following Table-4. Most polycyclic aromatic hydrocarbons were founded with different degree in all the samples. It is suggested that the detection rate was higher in developed industrial areas and range of vehicle location.

\section{ACKNOWLEDGEMENTS}

This paper was supported and translated by G.Q. Zhang from Weichai Power Co., Ltd. 
ANALYTICAL RESULTS OF REAL SOIL SAMPLES

\begin{tabular}{|c|c|c|c|c|}
\hline Compounds & $\begin{array}{l}\text { Sample1 } \\
(\mu \mathrm{g} / \mathrm{Kg})\end{array}$ & $\begin{array}{c}\text { Sample2 } \\
(\mu \mathrm{g} / \mathrm{Kg})\end{array}$ & $\begin{array}{l}\text { Sample3 } \\
(\mu \mathrm{g} / \mathrm{Kg})\end{array}$ & $\begin{array}{c}\text { Sample4 } \\
(\mu \mathrm{g} / \mathrm{Kg})\end{array}$ \\
\hline Acenaphthene & 6.9 & 23.6 & 15.6 & 12.3 \\
\hline Acenaphthylene & 63.8 & 86.7 & - & - \\
\hline Acenaphthene & - & 109.6 & 32.6 & - \\
\hline Fluorene & 56.3 & 10.9 & 26.3 & 7.8 \\
\hline Phenanthrene & 132.6 & 168.4 & 47.8 & 18.5 \\
\hline Anthracene & 214.6 & 325.6 & 29.6 & 6.3 \\
\hline Fluoranthene & 260.8 & 290.4 & 44.6 & 19.6 \\
\hline Pyrene & 68.4 & 66.5 & 14.3 & 5.7 \\
\hline Benzo(a)anthracene & 326.7 & 276.9 & 5.9 & 18.6 \\
\hline Chrysene & 86.4 & 283.9 & 6.5 & - \\
\hline Benzo(b)fluoranthene & 18.9 & 166.7 & 5.7 & 7.6 \\
\hline Benzo(k)fluoranthene & 23.8 & 236.9 & 4.3 & - \\
\hline Benzo(a)pyrene & 23.4 & 189.4 & 10.9 & 5.6 \\
\hline Indeno(1,2,3-cd)pyrene & - & 19.5 & - & - \\
\hline Dibenz(a,h)anthracene & 34.2 & - & 3.2 & - \\
\hline Benzo(g,h,i)perylene & 15.4 & 29.8 & - & - \\
\hline
\end{tabular}

\section{REFERENCES}

1. X.M. Zhang, Z.Q. Zhang and W.P. Huang, Environ. Sci. Manag., 7, 124 (2010).

2. L.L. Tang, X.Y. Tang, Y.G. Zhu and Q.L. Miao, J. PLA Univ. Sci. Technol., 2, 95 (2004).

3. H. Zeng, H. Tang, D.Z. Chen, G.N. Wang, J. Feng, J.Y. Wang and L. Li, Chin. J. Anal. Lab., 9, 11 (2011).
4. F.Q. Fan, J.F. Dou, A.Z. Ding, H.Y. Chen and Y.C. Du, J. Beijing Normal Univ. (Nat. Sci.), 3, 296 (2011).

5. Y.M. Jiang, S.Z. Wei, B.D. Xi, H.Y. Zhang and H.J. Li, Ecol. Environ. Sci., 3, 1176 (2009).

6. G.Y. Yang, T.B. Zhang, S.T. Gao, Z.X. Guo, H.F. Wan and Y.X. Gao, Environ. Sci., 10, 2350 (2007).

7. L.F. Zhang, X.J. Li, C.X. Liu and Z.R. Zeng, Chin. J. Anal. Chem., 9, 1269 (2007).

8. L.L. Ma, W.J. Lao, X.T. Wang, H. Liu, S.G. Chu and X.B. Xu, Chin. J. Anal. Chem., 9, 1025 (2003).

9. Z. Rao, S. Li, M. He and J. Su, Chin. J. Anal. Chem., 7, 954 (2007).

10. Q.L. Li, X.Q. Xu, X.C. Li and X.R. Wang, Science In China Ser. B Chemistry, 3, 202 (2006).

11. S.C. Zou, S. Shuai, T.G. Luan, H.Q. Zhang and Q. Shen, Chin. J. Anal. Chem., 6, 889 (2006).

12. Q. Zhang, X.W. Liu, M. Luo, L. Wang, H. Li, D. Wang and Y.P. Xu, Environ. Chem., 4, 771 (2011).

13. X.Z. Zhang, F.J. Luo, G.M. Liu, Z.Y. Lou and Z.M. Chen, Chin. J. Anal. Chem., 9, 1131 (2011).

14. S.X. Guan, Z.J. Yu, H.N. Yu, C.H. Song, Z.Q. Song and Z. Qin, Chromatographia, 73, 33 (2011).

15. P.C. Abhilash and N. Singh, Bull. Environ. Contam. Toxicol., 81, 604 (2008).

16. Y.-H. Wang, X. Li, X.-M. Zhou and L.-Y. Bai, Asian J. Chem., 24, 2042 (2012).

17. J. Shi, W. Gong, Y.S. Cheng, H.M. Liu and J.L. Cai, Chem. Online, 6, 467 (2007).

18. X.M. Li, Q.H. Zhang, P. Wang, Y.M. Li and G.B. Jiang, Chin. J. Anal. Chem., 11, 1641 (2011).

19. H. Zeng, H. Tang, D.Z. Chen, G.N. Wang, J. Feng, J.Y. Wang and L. Li, Chin. J. Anal. Lab., 9, 11 (2011).

20. X.C. Jiao, G. Wang, C.Y. Ye, X.D. Liu, Y.L. Yang and X.C. Wang, Rock Miner. Anal., 3, 207 (2011).

21. L.S. Wang and L. Zhang, J. Miner. Petrol., 23, 44 (2003). 